Fordham Law School

FLASH: The Fordham Law Archive of Scholarship and History

Faculty Scholarship

2020

Criminal Histories and Criminal Futures

Youngjae Lee

Follow this and additional works at: https://ir.lawnet.fordham.edu/faculty_scholarship

Part of the Criminal Law Commons 


\section{Criminal Histories and Criminal Futures}

Richard S. Frase and Julian V. Roberts. Paying for the Past: The Case Against Prior Record Sentence Enhancements. New York: Oxford University Press, 2019, 336 pp., \$74.00 (hardback), ISBN 978-0-190-25400-1

\section{Youngjae Lee}

To cite this article: Youngjae Lee (2020) Criminal Histories and Criminal Futures, Criminal Justice Ethics, 39:2, 143-151, DOI: 10.1080/0731129X.2020.1792094

To link to this article: https://doi.org/10.1080/0731129X.2020.1792094

曲 Published online: 03 Aug 2020.

Submit your article to this journal $₫$

Џ Article views: 95

Q View related articles $₫$

View Crossmark data [ᄌ 


\section{Criminal Histories and Criminal Futures}

\section{YOUNGJAE LEE*}

Richard S. Frase and Julian V. Roberts. Paying for the Past: The Case Against Prior Record Sentence Enhancements. New York: Oxford University Press, 2019, 336 pp., \$74.00 (hardback), ISBN 978-0-190-25400-1

In the United States and elsewhere, when a person with a criminal record is convicted of a new crime and is sentenced, his or her criminal record plays a significant role in the sentencing determination. But in what way exactly is the criminal record taken into account, and can we justify the practice? Richard Frase and Julian Roberts ${ }^{\prime 1}$ book, Paying for the Past: The Case Against Prior Record Sentence Enhancements, undertakes a detailed study of this topic by focusing on sentencing data from jurisdictions that employ sentencing guidelines in the United States. The authors ultimately conclude that "across US guidelines systems (and likely in other jurisdictions as well), repeat offenders are routinely subject to levels of punishment that cannot be justified," and that "the magnitude and rigidity of prior record enhancements in the United States generate

*Youngjae Lee is Professor of Law at Fordham University School of Law. Email: ylee@fordham.edu criminal penalties that are unnecessarily severe, undeserved, and harmful" (xiv). The literature on the issue of using the criminal record in sentencing is large at this point, due in significant part to the authors' sustained focus on this issue over time. ${ }^{2}$ Even so, the authors' amalgamation, analysis, and presentation of sentencing data, fair and detailed conclusions based on data, and sensible recommendations for reform make the book an invaluable source of insight and wisdom on an enormously consequential topic.

The authors define "criminal record" as "record of prior convictions" (xi), and a "guidelines system" as a sentencing system in which judges who sentence are presented with a set of recommended sentences for crimes where such recommended sentences are made by "a legislatively created sentencing guidelines commission," as opposed to by the legislature itself (238). Jurisdictions that meet this definition of "guidelines system" and are thus included in this study consist of 
seventeen states, the District of Columbia, and the federal jurisdiction. ${ }^{3}$ Among the guidelines systems, the authors distinguish between "grid" and "non-grid" systems. "Grid" systems (fourteen jurisdictions) take into account criminal history by assigning crimes to different rows and criminal history levels to different columns. A judge who is sentencing a person is to identify the correct row and the correct column to identify the applicable cell, which contains the recommended sentence. In "non-grid" guidelines systems (the remaining five jurisdictions), criminal history may be taken into account in different ways, through worksheets, recommended sentencing ranges, or applications of general principles (221-26).

The guidelines method is not the only way to take into account a person's criminal history. As the authors describe, in other common law jurisdictions like England and Wales, New Zealand, and Australia, judges are to take into account criminal history at sentencing, and how they do so is left to judicial discretion (3-4). The authors focus on guidelines systems because such systems collect extensive sentencing data and clearly articulate the role that criminal histories of individuals play at sentencing (xiii). At times, the authors focus only on grid systems among guidelines systems because it is easier to make comparisons among grid systems than to compare between grid and non-grid systems or between non-grid systems (91). And among grid systems, the authors sometimes single out North Carolina, Minnesota, Washington, and Kansas as points of comparison, as those jurisdictions show not only a range of the size of the prior record enhancement but are also easy to compare due to various features of the systems (159-61). However, general lessons derived from these systems should be applicable to all systems that consider criminal history when determining sentences.

So how does it all work? First, there is the matter of understanding the concept of "criminal record." As the authors emphasize, "criminal record" is made up of a number of different elements, and such elements are entered into criminal history "formulas" to generate a "criminal history score" or "criminal history points" in guidelines systems (5-7). The most obvious way in which the term "criminal record" is used is to refer to prior adult convictions for felonies, but there is more to it than that. Some jurisdictions count misdemeanors, and some jurisdictions include juvenile offenses, though both of those tend to weigh less in criminal history calculations than adult felony convictions (106). Does the number of convictions matter? In most guidelines systems, the answer is yes. Do violent crimes count more, and do prior crimes that are the same or similar to the current crime count more? The answers are yes and yes, at least in some jurisdictions. Also, a majority of guidelines systems add additional points to current offenses committed while under state custody or supervision stemming from prior convictions (106). Some, but not all, systems do not count old convictions or convictions that were followed by a significant crime-free period $(5,44-46,107$, 164, 166-69). The meaning of "prior" also can make a difference. In some jurisdictions, the prior conviction counts as a prior conviction only if it is entered before the current offense 
is committed, but, as the authors note, most guidelines systems count a conviction as a "prior" conviction as long as the "prior" conviction has been entered before the sentencing for the current offense, even if the current offense is committed before the prior conviction has been entered (108).

What exactly is the impact of criminal record, thus translated to criminal history scores, on sentencing? As the authors explain, the impact manifests in two ways. First, whether one has a criminal history can have a significant impact on whether one is imprisoned as opposed to receiving a "community-based," or noncustodial, sentence (91-96). Second, one's criminal history level has a significant impact on the duration of one's prison sentence (97-105). The authors dub these two effects "disposition" and "duration" effects respectively and show that they vary widely in different jurisdictions (90-105).

Both effects are important for those facing sentencing, as the "disposition" effect determines whether one goes to a prison, whereas the "duration" effect determines for how long one is to be in prison. To illustrate the importance of the "disposition" effect, the authors note that in $2014,32 \%$ of all persons sentenced to prison in Washington state were thus sentenced, as opposed to receiving a community-based sentence, solely because of their criminal records (95). That is, those sentenced would have been given noncustodial sentences for their offenses had they not had a criminal history. The "duration" effect varies across different types of offenses (98-100) and different jurisdictions (100-101). The authors report that, on average, "the recommended custody sentence for the most serious recidivist is more than six times longer than the sentence recommended for the first offender convicted of the same offense" (100). In the twelve jurisdictions studied to arrive at this average of six, the figures range from 1.7 (Washington, D.C.) to 14.4 (Kansas).

Criminal history thus plays an enormous role in sentencing determinations through disposition and duration effects, and, the authors argue, such sentencing determinations have greatly detrimental impacts on the overall criminal justice system and society. Namely, an emphasis on criminal history at sentencing can lead to outcomes that are contrary to the kinds of sentencing goals that should attract broad support, such as proportionality in sentencing, here defined as the idea that "more serious crimes should attract correspondingly more severe sanctions" (115), not housing in prisons those who commit nonviolent offenses, and not imprisoning those who are, due to their age, unlikely to reoffend (114-23). Criminal history's role in sentencing is also "a major contributor to racially disproportionate prison and jail populations" (151) and "greatly increase[s] prison bed needs and prison operating costs" (161).

Given such costs of the use of criminal record in sentencing determinations, what does society gain from the practice? Are there crime prevention benefits from the recidivist premium? There are many ways to imagine crime prevention benefits of increased sentences for repeat offenders. To think this through, let's imagine a number of people in a jurisdiction that employs a recidivist premium and call the persons $\mathrm{A}, \mathrm{B}$, C, D, E, and so on. A, B, C, and D commit a crime together. A, B, and C 
are then caught and punished, whereas $\mathrm{D}$ evades detection. $\mathrm{A}$ is a first-time offender, $\mathrm{B}$ is a secondtime offender, and $C$ is a third-time offender. $\mathrm{D}$ is a first-time offender, too, but is not caught. E has not committed a crime. A receives a noncustodial sanction whereas $B$, due to his criminal history, is sentenced to prison. C, due to his enhanced criminal history, receives a longer prison sentence than the one $B$ receives.

What is the impact of this sort of policy on crime prevention? The rationale of the policy might be to incapacitate those who are most likely to reoffend, and one might expect fewer crimes to be committed once $\mathrm{A}, \mathrm{B}$, and $\mathrm{C}$ are incapacitated. In this scenario, let's say, then, that, as one might hope, A, B, and C do not commit another crime while being sanctioned, custodial or not. Does this lower the crime rate in the society? Not necessarily. The crime rate may stay the same if $\mathrm{D}$ continues to commit crimes by himself or simply recruits a new person, $E$, to commit a crime. One might then say this shows that we have to be better at catching someone like D. Perhaps, but that still not would not prevent $E$ from taking D's place and recruiting, F, G, H, and so on. This is the sense in which punitiveness may not lead to an overall crime reduction, as long as the market for criminals is in operation, where there is a "demand" for criminal activities and a "supply" of those willing to engage in such conduct (74). But does the recidivist premium, by making salient the consequences of living a life of crime, not serve as warning to deter D, E, F, G, H and so on? By increasing the severity of sanctions for those with criminal history, one can perhaps deter persons with no criminal histories and prevent them from entering the market for offenders, or at least make it less likely. The authors, though, doubt that this is the case, noting that " $[\mathrm{t}]$ he research literature on incapacitation ... casts considerable doubt on the benefits of recidivist sentencing premiums as a crime control measure" (73). They also note studies showing generally that changes in the severity of punishments have little impact on aggregate crime rates (74).

Could we hypothesize at least that $B$ and $C$ learn their lessons from being punished more harshly as repeat offenders, and that such increased punishments make them less likely to reoffend, even if the overall crime rate does not change? That is, if $\mathrm{B}$, a second-time offender, is not given a prison sentence and if such leniency might make B more likely to reoffend, then the decision to impose a prison sentence due to his criminal record would make sense. But the authors doubt this is the case, as their review of studies leads them to conclude that "prison is not associated with lower recidivism rates than less severe penalties," and cites several studies, including one showing that "re-offending rates were lower for offenders assigned to a community sanction rather than a custodial order" (80). What about the impact of the longer prison sentence on $C$ for being a third-time offender? That is, if $\mathrm{C}$, a third-time offender, were not given a longer prison sentence, and were instead treated just like B, a second-time offender, then perhaps the shorter sentence would make C more likely to reoffend once $C$ is released. The authors doubt this is the case as well, again discussing several studies and noting especially 
one study's conclusion that there is "no clear effect of length of imprisonment on recidivism" (82). In fact, the authors note, "there is ... a mild but detectable criminogenic short-term effect of imprisonment," as "prison is associated with slightly higher reoffending rates" when "compared to community-based sanctions," and "for some offenders, longer prison terms increase the odds of further crime" (88).

Perhaps the differing treatments of A, B, and C can be justified as a way of keeping control over those who are likely to reoffend. Guideline systems make, after all, as the authors note, an assumption that "prior convictions provide a useful proxy for recidivism risk" (41). The authors observe that "that assumption is well supported by research" (41) in that "[r]esearch has repeatedly shown that, in general, repeat offenders have a higher risk of re-offending than first offenders, and that recidivism risk generally rises with increases in the number of prior convictions" (42). In that case, the emphasis on criminal history at sentencing seems to make sense as a general matter, but that is not all there is to it.

First, even if criminal record is a reliable predictor of recidivism, there is a separate question as to whether guidelines' designs appropriately track the data on the relationship between criminal record and recidivism risk. As suggested above in the example of A, B, and C, a typical guideline assigns a sanction to an offense for someone with no criminal history and then increases the severity of the sanction in a linear fashion as the criminal history score increases, though the precise way in which the sanction increases varies (7-8). The sanctions may increase by a fixed percentage as criminal history increases or by a fixed number of months (8), though the "slope" of the increase varies across different jurisdictions, and within jurisdictions depending on the seriousness of offenses (97-101).

Despite these variations, the authors argue that the guidelines all suffer from the same problem: a linear function is not justified by the data on recidivism risk. Focusing on studies of three jurisdictions federal, Minnesota, and Pennsylvania - the authors point out that the difference in recidivism risks of those in the lowest criminal history category (call it level 1) and those in the next level up (call it level 2) is much bigger than the corresponding differences between those in level 2 and those in level 3, between those in level 3 and those in level 4, and so on (49). In fact, the recidivism risk does not increase significantly once criminal history hits a certain level (50-51). The current design of guidelines assumes a constant increase across criminal history categories, and, as a result, "a dramatic increase in severity is often imposed to achieve what appears to be a modest increase in prevention" (52). The authors conclude that the current guidelines are in this respect "unsupported by the recidivism research," given that "as a general rule, minor increases in ascribed risk should attract equally modest increments in severity" (52).

Second, the authors note that in many guidelines systems "an offender's prior convictions never go away" (164), and argue that such an eternal-record approach cannot be justified given that people's risk of offending declines over time as they age $(64,161,164,170,179)$ and that 
research shows that "offenders with a crime-free gap of seven or more years have much lower recidivism risk than offenders with shorter gaps" (179). The authors are similarly critical of the practice of counting juvenile offenses (though the authors concede some uncertainty over whether juvenile priors are predictive of higher adult recidivism risk, given mixed studies) (184-88) and adult misdemeanor convictions (given that "most people commit minor criminal violations at some point," while including misdemeanor priors into criminal history scores makes such scores only slightly more predictive of recidivism) (188-89). The authors also question the practice of taking into account a person's custody status at the time of reoffending (seeing "limited research validation" on whether the factor predicts a higher risk of recidivism) (196), similarity of current offense to previous offenses (noting that "the limited empirical research has generated inconsistent findings" on the predictive power of similarity in offenses committed over time) (197-203), and seriousness of previous offenses (noting that "the severity level of prior crimes is not a good predictor of either the frequency or the severity of later offending") (203-5).

Third, guidelines systems may be not only taking into account factors that are poor predictors of risk of recidivism, but may also be failing to take into account factors that are predictive of recidivism. Are there other, potentially better, predictors of likelihood of reoffending? The generalization that "repeat offenders have a higher risk of re-offending" (42) may be valid, but there are other factors that are predictors of recidivism, either by themselves or in combination with criminal history. The authors note that age, gender, substance abuse, employment history, "criminal thinking patterns," and "antisocial personality features" are also good predictors of re-offending (64). Some guidelines systems, though not all, take some of these factors into account (61-69).

In sum, criminal history plays a huge role at sentencing in guidelines jurisdictions, such sentencing practices carry enormous costs, and the benefits gained from them are small, especially because the guidelines are poorly designed and applied in ways that are not supported by data.

The authors make a number of recommendations for reform, such as: not counting juvenile adjudications and adult misdemeanors for criminal history determinations (212-13), having adult convictions "decay" and "expire" after a number of years (213), not enhancing on the basis of custody status of a person at the time of the current offense (214-15), adjusting the slope of the increase in severity of sanctions as criminal history accumulates so that it is not a straight line up at an angle, but rather resembles an ice-hockey stick held upside down (a sharp incline between the first two criminal history categories and then much smaller increases as criminal history increases) $(112,215-16)$, putting a cap on the size of the recidivist premium so that the sentence for an offense by a person in the highest category of criminal history is never more than twice the sentence for the same offense by a person in the lowest category of criminal history (216), imposing imprisonment "only where the current offense is of at least a medium level of severity, and where the current and at least one prior crime involved actual violence or 
potential for serious harm" (217), and giving judges discretion to depart from guidelines when they sentence (218).

One issue I have not mentioned thus far is the issue of desert: Are repeat offenders more blameworthy than first-time offenders? If $\mathrm{A}$ and $\mathrm{B}$ commit a crime together and are prosecuted and sentenced, and $\mathrm{A}$ and $\mathrm{B}$ are equal in every way except that $A$ is a first-time offender and $B$ is secondtime offender, is B more blameworthy than A? There is a widespread intuition that a second-time offender is more blameworthy than a first-time offender and that punishments ought to reflect such differences, and sentencing guidelines typically mention this intuition in explaining their treatments of criminal history (23-24). However, as we have seen, "criminal record" is not a simple unidimensional metric, as there are many different ways to incorporate criminal record into sentencing, and a simple, vague intuition that repeat offenders deserve more can neither prescribe nor justify particular sentencing practices. More detailed theoretical prescriptions are needed, and such prescriptions cannot be devised without a fuller theory that gives an account of the culpability of repeat offending.

The authors survey and evaluate different proposals that have been defended by desert theorists, from those that say that criminal history does not increase culpability, to those that say that lack of criminal history should be a mitigating factor only, and to those that say presence of criminal history should be an aggravating factor (24-38). The authors identify an area of consensus among these theorists and conclude that "[n]o retributive account justifies a powerful role for previous convictions as an aggravating factor at sentencing" and that "in terms of the foundational justification for taking a prior record into account, the retributive analysis is less compelling than the risk-based rationales" (38-39). This conclusion allows the authors to give considerations of desert a secondary role in the book and to focus instead on the question of the relationship between criminal history and recidivism risk (39). However, because the authors are committed to the general principle that punishments must be "justified both by principles of desert and by crime prevention goals" (209), they return to the issue of desert and seek, throughout the book, to "ensure that criminal history enhancements do not depart markedly from the requirement of offense-based proportionality" (39).

For instance, the authors discuss my desert-based argument that people who are convicted and punished incur a special obligation to set their life straight, and that their reoffending indicates a failure to do so, thereby increasing the risk of further reoffending (35-36). This theory, I have argued previously, implies that the recidivist premium should not be larger than the punishment for the offense without the recidivist premium, since the additional wrong essentially consists of risking reoffending, as opposed to committing the second offense itself. ${ }^{4}$ The authors note that this conclusion is consistent with their view that "offenders with the longest records should not receive penalties more than twice as severe as the penalties given to first offenders who commit the same offense" (36). I have also previously argued that my proposed desert account of repeat offenders implies that "repeat offenders ought to be able to present the ways in which they have tried to steer clear of 
criminality and, depending on the reasonableness and sincerity of their attempts, receive a reduction in the recidivist premium." ${ }^{5}$ The authors note their agreement with this view as well (19), as they argue that "the rising culpability of repeat offending should only be a presumption, rebuttable by the offender" if the offender "has taken steps to correct the causes of his reoffending" (39). The authors also note, and I agree, that an implication of my particular account is that "any period of desistance ... is worthy of praise and makes the offender less culpable for later crimes" (172), which supports the authors' recommendation that the impact of previous convictions should diminish over time and expire at some point (178-81). Finally, I have also argued in favor of mitigation when the government has made it difficult for a person to resume a law-abiding life by placing numerous roadblocks to reintegration in the form of collateral consequences. ${ }^{6}$ Similarly, the authors show some sensitivity to the issue of the state's own role in producing criminality, especially in minority communities, through "criminogenic consequences of imprisonment" (83), "compound[ing of] individual, family, and community disadvantage," and "reinforce(ment of) the perception ... of systemic and societal unfairness," which "undermines the effectiveness of punishment and crime control effects generally" (132). All in all, the authors' careful attention throughout the book to the question of desert, even as they focus mainly on the question of the relationship between criminal history and recidivism risk, is one of many strengths of this book.

A question to which the authors devote only a limited amount of space, but that will become increasingly important in sentencing policy, is the use of various risk-assessment tools in sentencing decisions. ${ }^{7}$ This book is not about that trend, but about taking stock of what we know after decades of experience with sentencing guidelines. The authors do note the existence and increasing use of risk assessment tools and cautiously endorse them, as they favor "improv [ing] the accuracy and efficiency of predicted risk" by taking into account "at least some of the welldocumented risk factors beyond criminal history" in a variety of ways (71). The authors also recommend placing persons in different risk categories (216-17), though they are aware of some of the legal and ethical difficulties associated with such a practice (84-87). Technological improvements and the growing popularity of riskassessment instruments are likely to lead us into a world in which criminal history ends up becoming just one of many factors that decision makers use to issue "risk reports" on individuals. Some day we may even reach a state where new generations wonder what all the fuss about criminal history was about, but in that new world, scrutinizing our sentencing tools from the moral perspective will not cease to be relevant. Questions about desert, questions about the relevance of desert to criminal law and punishment, and moral reflections about responsibility and culpability are going to be of continued pressing importance. This book does something that will be of lasting significance through all the flashy new trends and advances - it provides a model of evidence-informed criminal justice policy making that does not lose sight of considerations of morality and humanity. 


\section{Disclosure Statement}

No potential conflict of interest was reported by the author(s).

\section{Notes}

1 Although the book lists Richard Frase and Julian Roberts as the authors, Rhys Hester is credited as a third co-author of chapters five through eight. For the sake of simplicity, this review uses the term "authors" to refer to either "Frase and Roberts" or "Frase, Roberts, and Hester" without distinguishing between the two uses.

2 See e.g. Frase, Just Sentencing; Roberts, Punishing Persistent Offenders; Roberts and Von Hirsch, Previous Convictions at Sentencing. This journal has had a role in the history of this literature as well, by, in part, printing an early, significant intervention in the literature in its very first volume. See Fletcher, "The Recidivist Premium"; see also Von Hirsch, "Criminal Record Rides Again." As the authors note throughout the book, I have taken part in this debate as well. See Lee, "Recidivism as Omission"; Lee, "Repeat Offenders."

3 The seventeen states are Alabama, Arkansas, Minnesota, Delaware, Florida, Kansas, Maryland, Massachusetts, Michigan, North Carolina, Ohio, Oregon, Pennsylvania, Tennessee, Utah, Virginia, and Washington (238).

4 See Lee, “Recidivism as Omission," 618.

5 See ibid., 616.

6 See ibid., 618-20.

7 See Garrett and Monahan, "Judging Risk"; Huq, "Racial Equity"; Collins, "Punishing Risk"; Starr, "Evidence-based Sentencing."

\section{Bibliography}

Collins, Erin. "Punishing Risk." Georgetown Law Journal 107, no. 1 (October 2018): 52-57.

Fletcher, George P. "The Recidivist Premium." Criminal Justice Ethics 54, no. 2 (Summer/ Fall 1982): 54-59.

Frase, Richard S. Just Sentencing. New York: Oxford University Press, 2013.

Garrett, Brandon L., and John Monahan. "Judging Risk." California Law Review 108, no. 2 (April 2020): 439-493.

Von Hirsch, Andrew. "Criminal Record Rides Again." Criminal Justice Ethics 10, no. 2 (Summer/Fall 1991): 2-56.

Huq, Aziz Z. "Racial Equity in Algorithmic Criminal Justice." Duke Law Journal 68, no. 6 (March 2019): 1043-1134.

Lee, Youngjae. "Recidivism as Omission: A Relational Account." Texas Law Review 87, no. 3 (February 2009): 571-622.
Lee, Youngjae, "Repeat Offenders and the Question of Desert." In The Role of Previous Convictions at Sentencing: Theoretical and Applied Perspectives, edited by Julian V. Roberts and Andrew Von Hirsch, 49-71. Oxford: Hart Publishing, 2010.

Roberts, Julian V. Punishing Persistent Offenders: Exploring Community and Offender Perspectives. New York: Oxford University Press, 2008.

Roberts, Julian V., and Andrew von Hirsch, eds. Previous Convictions at Sentencing: Theoretical and Applied Perspectives. Oxford: Hart Publishing, 2010.

Starr, Sonja. "Evidence-based Sentencing and the Scientific Rationalization of Discrimination." Stanford Law Review 55, No. 4 (April 2014): 803-872. 